\title{
Pitfall trap efficiency: do trap size, collecting fluid and vegetation structure matter?
}

\author{
Matti Koivula*, D. Johan Kotze, Laura Hiisivuori \& Hannu Rita
}

Koivula, M., Kotze, D. J., Hiisivuori, L. \& Rita, H. 2003: Pitfall trap efficiency: do trap size, collecting fluid and vegetation structure matter? - Entomol. Fennica 14: 1-14.

Apart from experimental design, the selection of pitfall trap size, collecting fluid and habitat type sampled may also influence the capture efficiency of the method. We combined three field studies from two very different geographic areas, in which the efficiency of pitfall traps, using carabid beetles (Coleoptera: Carabidae), is evaluated. First, we showed that ethylene-glycol is a more efficient collecting fluid compared to commercial anti-freeze, paraffin and salt water in collecting beetles in a forest patch in South Africa. Second, we showed that larger traps (90 $\mathrm{mm}$ mouth diameter) are more efficient in collecting carabids than small traps $(65 \mathrm{~mm})$ in a meadow in Finland. We also showed that for these large traps, commercial vinegar was a better collecting fluid than propylene-glycol, but that for small traps, propylene-glycol was superior to vinegar in collecting carabids. Finally, we showed that the trappability of Pterostichus oblongopunctatus and Carabus hortensis differed in enclosures placed into two different habitat types (a forest and a clear-cut in Finland), while trappability did not differ significantly for two other species (Calathus micropterus and Pterostichus niger) in these habitat types. However, for the two Pterostichus species studied, the catches in traps placed in the centre of the enclosures were slightly higher in the clear-cut, compared to the forest, and catches were higher in enclosures with rich field-layer vegetation, compared to enclosures with poor vegetation. The three studies re-emphasise the uncertainties of using pitfall traps in ecological studies. However, with careful planning and standardisation to help avoid erroneous interpretations, pitfall trapping is an invaluable method for the field ecologist.

Matti Koivula, D. Johan Kotze \& Laura Hiisivuori, Department of Ecology and Systematics, P.O. Box 65, FIN-00014 University of Helsinki, Finland; (*E-mail:matti.koivula@helsinki.fi)

Hannu Rita, Department of Forest Resource Management, P.O. Box 27, FIN00014 University of Helsinki, Finland

Received 30 August 2002, accepted 5 November 2002 


\section{Introduction}

The use of pitfall traps for monitoring the number and activity of surface dwelling invertebrates is well known (Greenslade 1964, Luff 1975, Baars 1979, Halsall \& Wratten 1988, Spence \& Niemelä 1994, Ward et al. 2001), and the method has contributed substantially to our understanding of the pattern and comparative dynamics of epigaeic invertebrate assemblages. Pitfall traps are simple to use, inexpensive, provide a large return for time and money committed, and collect specimens continuously, including night foragers, so overcoming interspecific differences in circadian activity rhythms (Southwood 1978, Törmälä 1982, Samways 1983, Marsh 1984, Donnelly \& Giliomee 1985, Huusela-Veistola 1996, Ward et al. 2001).

The application of the method has, however, not been without controversy (see Den Boer 1986). Criticisms of the method usually focus on its limited value in the direct estimation of population levels, or in comparing populations or assemblages (Southwood 1978, Den Boer 1986). Furthermore, species-specific behaviour in terms of movement activity periods and trappability (Greenslade 1964, Luff 1996) can bias results, even between species of the same genus (Mommertz et al. 1996). Pitfall trap catches are also influenced by climate, habitat structure, food availability, seasonally changing behaviour (which may differ between the sexes of a species), and even by the hunger level of the animal (Wallin \& Ekbom 1994, Purvis \& Fadl 1996).

The main factors that affect pitfall catches can be divided into three: trapping technique, structure of the habitat(s) to be sampled, and specific characteristics of the animals to be caught (Mommertz et al. 1996). Investigators have no control over the second and third factors, but do control trapping technique. Although there is no universally accepted placement and design of traps (Van den Berghe 1992), optimising these can improve efficiency. This was shown by Spence \& Niemelä (1994) who compared capture efficiencies of different traps, and by Ward et al. (2001) who studied the effects of inter-trap distances on surface arthropod catches. Apart from placement and design, collecting fluid used can also strongly influence catches (Luff 1975, Holopainen 1992, Lövei \& Sunderland 1996).
Using ground beetles (Coleoptera: Carabidae), a group commonly collected in pitfall traps, we investigated three questions, two of which involve pitfall trap design, and one habitat structure. First, we tested the relative efficiency of four pitfalltrap collecting fluids used commonly in the sampling of epigaeic invertebrates. These include an ethylene glycol:water (3:1) mixture, commercial anti-freeze, commercial paraffin, and salt water. Second, in a two-way design we tested the effects of pitfall trap size ( $65 \mathrm{vs} .90 \mathrm{~mm}$ mouth diameter) and collecting fluid (a propylene-glycol:water (1:1) mixture vs. commercial vinegar) on carabid beetle catches, both in terms of number of individuals and species collected, and in terms of species-specific trap efficiency. We expect the following from these two studies; (a) to collect more beetles in traps filled with ethylene or propylene glycol compared to traps filled with salt water (see Holopainen 1992 and references therein), commercial anti-freeze, paraffin or vinegar (probably because of the strong smells of these chemicals), and (b) to collect more individuals and species in the larger traps (because of the larger collecting area of these traps, see Brennan et al. 1999). Additionally, we quantify the ratio of male to female Pterostichus niger Schaller and $P$. melanarius Illiger individuals collected in the pitfall traps. These species were chosen because they are usually abundantly collected, and distinguishing sex is straightforward (see Lindroth 1985, 1986). True sex ratios are difficult to obtain from the literature, and the reported ones are based on pitfall catches. For example, Holopainen (1992) showed that in most carabid species collected by him, significantly more females were collected using ethylene glycol pitfall traps, while significantly more males were collected in some species where water-filled pitfall traps were used.

Third, we tested the efficiency of pitfall traps in different habitat types by comparing the number of released individuals of four carabid species (Calathus micropterus [Duftschmid], Carabus hortensis L., Pterostichus oblongopunctatus [F.] and Pterostichus niger) collected in enclosures placed in a forest patch and in a clear-cut. In unfenced habitat we expect to collect the first three forest dwelling species (Lindroth 1985, 1986) more frequently in forest habitat, and P. niger a forest/ open-habitat generalist (Kinnunen 1999) in equal 
numbers in forests and clear-cuts. This is because carabid beetles usually display random walking behaviour in favoured habitat, compared to directed movement behaviour in unfavourable habitat (Wallin \& Ekbom 1988, Charrier et al. 1997). However, in the enclosures we anticipate the catches to be higher in the unfavourable habitat, because the enclosure walls may guide the beetles displaying directed movement behaviour into the pitfall traps placed at the enclosure corners, more so than for beetles which move randomly. This expectation is, however, conditioned on the assumption that overall beetle activity is unchanged from favoured to unfavourable habitat. If not, we anticipate a difference in carabid catch in the traps in the centre of the enclosures (i.e. traps not influenced by the enclosure walls) in the different habitat types.

\section{Material and Methods}

\subsection{Collecting fluid study}

This part of the study was performed in the Karkloof forestblock (29 $\left.19^{\prime} \mathrm{S} 30^{\circ} 16^{\prime} \mathrm{E}\right)$, KwaZulu-Natal, South Africa. This forest-block forms part of the greater mistbelt-forest complex, which is situated on the southeastern slopes of the Drakensberg mountain range. The study site was dominated by the following tree species: Cape plane (Ochna arborea), Outeniqua yellowwood (Podocarpus falcatus), Henkel's yellowwood ( $P$. henkelii), White violet-bush (Rinorea angustifolia), Sneezewood (Ptaeroxylon obliquum), Common spike-thorn (Gymnosporia buxifolia), Common turkey-berry (Canthium inerme) and Lemon wood (Xymalos monospora). Traps were visited four times, twice a month, between the beginning of October and the end of November 1997, the South African spring season.

Plastic pitfall traps used had a mouth diameter of $75 \mathrm{~mm}$ and a depth of $85 \mathrm{~mm}$. A gridsect trap layout was used to collect the ground beetles. Sixteen grids were placed along a line transect within a Karkloof forest patch. Each grid consisted of 16 traps, arranged in four sets of four (Fig. 1a). Four commonly used collecting fluids were used here: an ethylene glycol:water (3:1 ratio) mixture, commercial antifreeze (with ethylene glycol as a major component), commercial paraffin, and salt water. Distances between traps, sets and grids are shown in Fig. 1a. Unfortunately the four traps per set, i.e. the collecting fluids, were not placed randomly, and the traps were placed rather close to one another so that the collecting fluids used may influence the catch in adjacent traps. We discuss these problems later.

A one-way ANOVA was used to test the null hypothesis of no difference in carabid abundance and species richness between the four collecting fluids used.

\subsection{Trap size and collecting fluid study}

In 1999 we placed 40 pitfall traps in a meadow (homogeneous to the human eye) near Nuuksio National Park $\left(60^{\circ} 16^{\prime} \mathrm{N}\right.$ $24^{\circ} 40^{\prime} \mathrm{E}$ ), southern Finland. The study site was a moist meadow with scattered willows (Salix spp.), where the main plant genera were Agrostis, Alopecurus, Calamagrostis, Hierochloe and Phleum grasses. Filipendula, Hypericum, Vicia and Trifolium species were also abundant. Brachytecium mosses were abundant in dry areas where the grasses did not cover the whole bottom layer. Trapping started on 7 June 1999 with traps visited twice (7 July, 10 August 1999), the Finnish summer season.

Pitfall traps were placed in five line transects $(10 \mathrm{~m}$ apart), each line containing eight traps ( $8 \mathrm{~m}$ apart). Twenty traps were large ( $90 \mathrm{~mm}$ mouth diameter), and 20 were small (65 mm mouth diameter). In 20 traps we placed commercial vinegar as collecting fluid, and in 20 a propyleneglycol:water (1:1) mixture. This resulted in 10 large traps with a propylene glycol:water mixture, 10 large traps with vinegar, 10 small traps with a propylene-glycol:water mixture and 10 small traps with vinegar. A systematic design (Fig. 1b) was employed to avoid inadequate interspersion of traps, a problem sometimes associated with randomisation designs in small experiments (Hurlbert 1984).

Data were analysed using a Model I two-factor ANOVA, with trap size and collecting fluid as factors. Pterostichus melanarius and $P$. niger sex ratios were calculated on the mean numbers of individuals collected from the 20 small traps (propylene-glycol and vinegar fluids pooled), and from the 20 large traps (propylene-glycol and vinegar traps pooled) separately. Sex ratios from small and large traps were calculated separately because trap size had a significant effect on catch, while collecting fluid appeared not to influence catch (see Results section and Table 2b).

\subsection{Habitat type study}

This part of the study was done in Lammi $\left(61^{\circ} 04^{\prime} \mathrm{N} 24^{\circ} 54^{\prime} \mathrm{E}\right)$, southern Finland, during the summer of 2001. We selected a recently clear-cut stand (approximately $2-3$ hectares; logged 1.5 years before the experiment) with an adjacent mature forest stand. Both stands represented a Myrtillus-type (Cajander 1949) forest, where Norway spruce (Picea abies [L.] Karst.) is the dominant tree species in the mature phase. The field layer was mainly dominated by Calamagrostis and Deschampsia grasses in the clear-cut, and Vaccinium myrtillus and $V$. vitis-idaea dwarf shrubs in the forest stand.

We placed eight $2 \times 2 \mathrm{~m}$ enclosures (styrene panels, $30 \mathrm{~cm}$ high, no roof cover, partly dug into the ground layer) in the clear-cut and eight in the forest stand (Fig. 1c). The enclosure material was hard and smooth and thus probably prevented the beetles from escaping from the enclosures. Four enclosures in each habitat type were in sites where the field-layer vegetation was well developed (percentage cover between $50 \%$ and $100 \%$ ), and four were in sites which only 


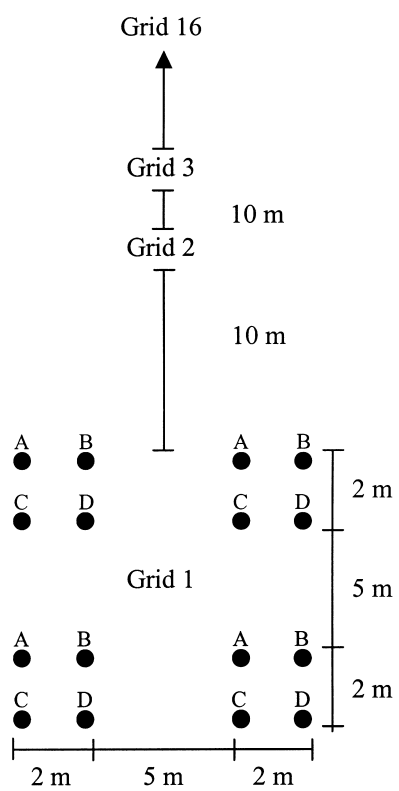

$\mathrm{A}=$ Ethylene-glycerol

$\mathrm{B}=$ Anti-freeze

$\mathrm{C}=$ Paraffin

$\mathrm{D}=$ Saltwater

\begin{tabular}{|l|l|l|l|l|} 
& \multicolumn{1}{|c|}{$40 \mathrm{~m}$} \\
\hline LV1 & SV1 & LG1 & SG1 & LV2 \\
\hline LG3 & SG2 & LV3 & SV2 & LG2 \\
\hline SV3 & LV4 & SG3 & LG4 & SV4 \\
\hline SG5 & LG5 & SV5 & LV5 & SG4 \\
\hline LV6 & SV6 & LG6 & SG6 & LV7 \\
\hline LG8 & SG7 & LV8 & SV7 & LG7 \\
\hline SV8 & LV9 & SV9 & LG9 & SV10 \\
\hline SG10 & LG10 & SG9 & LV10 & SG8 \\
\hline
\end{tabular}

$\mathrm{L}$ - Large traps (90 $\mathrm{mm}$ mouth diameter) $\mathrm{S}$ - Small traps (65 $\mathrm{mm}$ mouth diameter) $\mathrm{V}$ - Vinegar

G - Propylene-glycol:water

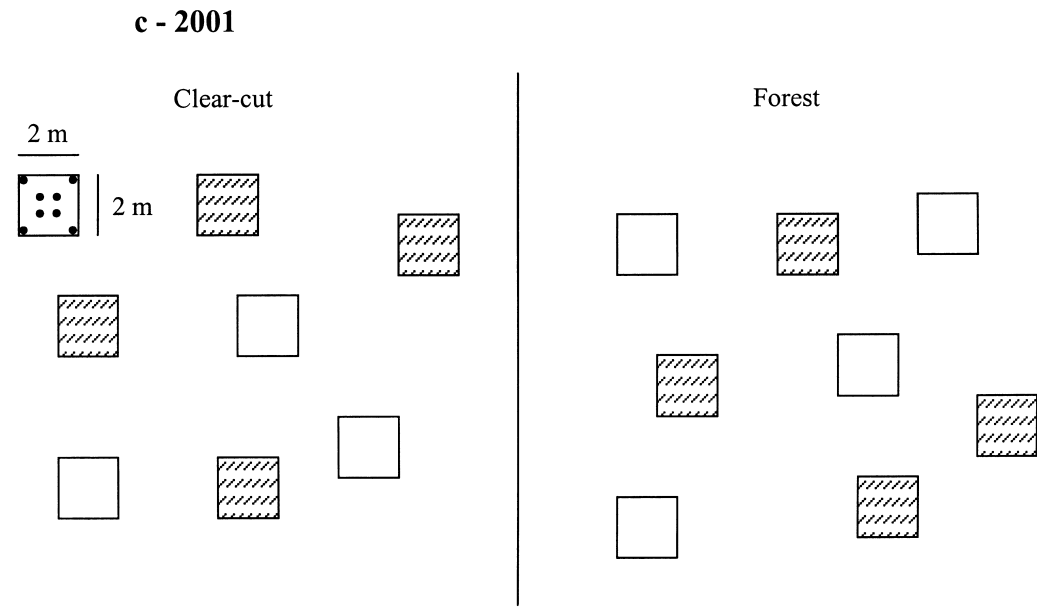

Fig. 1. The three study designs. - a. Gridsect sampling design in a homogeneous forest patch in Karkloof forest, South Africa, 1997. Each grid consisted of 16 traps arranged in four sets of four with the four collecting fluids placed within each set. - b. Sampling design in a field near Nuuksio National Park, Finland, 1999, testing the effects of collecting fluid and trap size on carabid catch. - c. Sampling design in Lammi, Finland, 2001 , using $2 \times 2$ m enclosures (with eight traps per enclosure) to test trappability in poorly (open squares) and well-developed (shaded squares) field layers in clear-cut and forest.

had mosses and litter on the soil surface but no or little field-layer vegetation (percentage cover less than $10 \%$ ). Thus, we had four enclosures representing sites with no forest cover and scarce field-layer vegetation, four with no forest cover but where the field-layer vegetation was well developed, four with forest cover but scarce field-layer 
vegetation, and four with forest cover and abundant dwarf shrubs. We placed eight dry pitfall traps (mouth diameter $80 \mathrm{~mm}$, depth $105 \mathrm{~mm}$ ) into each enclosure: one in each corner, and four traps $(1 \times 1 \mathrm{~m}$ square $)$ in the centre of the enclosure. The traps were covered with styrene roofs $(10 \times$ $10 \mathrm{~cm}$ ) in order to protect them from litter and rain. The immediate surroundings $(5-10 \mathrm{~cm})$ around each trap were cleared from field-layer vegetation.

Since the enclosures had no roofs, we focused the study on flightless carabid species. We collected individuals from sites next to the enclosures, and randomised them before releasing; for example, an individual caught from the clearcut was not necessarily released there. Each individual was marked by using model paint and nail varnish, before release into an enclosure. We released a total of 234 individuals of Calathus micropterus, 64 individuals of Pterostichus oblongopunctatus, 48 individuals of $P$. niger and 32 individuals of Carabus hortensis into the enclosures (Table 1). We released beetles in equal amounts into each enclosure in three release periods.

The release periods were separated by 'kill' pitfall trapping (salt water; between the periods), and we trapped out before the release experiment. We, therefore, assume that the density of individuals was not too high within the enclosures. In the 'kill' trapping before the experiment, for example, we caught from some enclosures as many as 12-14 individuals of $P$. oblongopunctatus. This leads to a minimum 'natural' density estimate of over 3 individuals $/ \mathrm{m}^{2}$, which is approximately the same or even higher than that in the experiment

Because of several zero catches during the catch periods, we pooled the dataset (recapture events per enclosure) but kept the species separate. The data were analysed using a Model I two-factor ANOVA, with field-layer vegetation (rich or poor) and habitat type (clear-cut or forest) as factors.

\section{Results}

\subsection{Collecting fluid study}

Carabid beetles are, taxonomically and ecologically, poorly known in South Africa, with the last major revision of the whole group more than a century ago (Péringuey 1896). Subsequently, we grouped the carabids collected here into 16 morphospecies (see Oliver \& Beattie 1993, 1996), with a collective abundance of 197 individuals.

Significantly more carabid individuals and species were collected from traps filled with the ethylene-glycol:water mixture than those with any other collecting fluid (Table 2a, Fig. 2). Traps filled with paraffin collected the lowest mean number of individuals and species. These results should be considered with caution because of an error in the experimental layout, i.e. even as great care was taken into placing the traps in homogenous forest habitat, a preexisting field gradient might have obscured these results (Hurlbert 1984). The 'left-hand side' of the experimental layout only had traps filled with ethylene-glycol and paraffin, while the 'right-hand side' of the layout only had traps filled with anti-freeze and salt water (see Fig. 1a). To correct for this mistake we should have randomised each set of four pitfall traps. Nevertheless, we did not observe obvious environmental gradients in the study area and are quite confident in the results presented here.

In absolute numbers, traps filled with ethylene-glycol:water trapped 101 (50\% of total catch) individuals and $11(69 \%)$ species, with commercial anti-freeze $46(23 \%)$ individuals and 7 (44\%) species, with commercial paraffin $10(5 \%)$ individuals and $6(38 \%)$ species, and with salt water $40(20 \%)$ individuals and $8(50 \%)$ species.

\subsection{Trap size and collecting fluid study}

A total of 43 carabid species and 1417 individuals were collected here (Appendix). Pterostichus

Table 1. Carabid individuals released into the experiment enclosures during the trapping periods in 2001. Release $=$ total number of individuals released, Capture $=$ total number of recapture events during the period. Captured beetles were re-released into the enclosures (and the same individual may thus have been caught more than once), which explains the sometimes higher number in Capture than in Release columns.

\begin{tabular}{|c|c|c|c|c|c|c|}
\hline \multirow[b]{2}{*}{ Species } & \multicolumn{2}{|c|}{ 4-15 June } & \multicolumn{2}{|c|}{ 15-24 July } & \multicolumn{2}{|c|}{ 16-23 August } \\
\hline & Release & Capture & Release & Capture & Release & Capture \\
\hline Calathus micropterus & 96 & 12 & 192 & 31 & 48 & 7 \\
\hline Carabus hortensis & - & - & - & - & 32 & 119 \\
\hline Pterostichus niger & - & - & 48 & 96 & 16 & 39 \\
\hline P. oblongopunctatus & 64 & 47 & - & - & - & - \\
\hline
\end{tabular}


Table 2. Analysis of variance results. - a. One-way ANOVA testing for differences in carabid beetle catch in four different collecting fluids. - b. Model I two-factor ANOVA testing for differences in catch using two different collecting fluids and two different trap sizes. $\mathrm{F}=$ females, $\mathrm{M}=$ males. $-\mathrm{c}$. Model I two-factor ANOVA testing for differences in catch of four carabid species in poorly and well-developed field layers (Field layer) in a clear-cut and forest patch (C_F).

\begin{tabular}{|c|c|c|c|c|}
\hline Source of Variation & df & MS & $\mathrm{F}$ & $p$ \\
\hline \multicolumn{5}{|c|}{$\begin{array}{l}\text { a. Collecting fluid study (KwaZulu Natal, South Africa) } \\
\text { Carabid abundance }\end{array}$} \\
\hline Collecting fluid & 3 & 1.109 & 15.831 & $<0.001$ \\
\hline Error & 60 & 0.070 & & \\
\hline \multicolumn{5}{|l|}{ Carabid species richness } \\
\hline Collecting fluid & 3 & 16.224 & 12.064 & $<0.001$ \\
\hline Error & 60 & 1.345 & & \\
\hline \multicolumn{5}{|c|}{$\begin{array}{l}\text { b. Trap size and collecting fluid study (Espoo, Nuuksio, Finland) } \\
\text { Carabid abundance }\end{array}$} \\
\hline Collecting fluid & 1 & 0.090 & 0.207 & 0.652 \\
\hline Trap size & 1 & 5.326 & 12.203 & 0.001 \\
\hline Collecting fluid $\times$ Trap size & 1 & 2.297 & 5.263 & 0.028 \\
\hline Error & 36 & 0.436 & & \\
\hline \multicolumn{5}{|l|}{ Carabid species richness } \\
\hline Collecting fluid & 1 & 0.591 & 0.100 & 0.754 \\
\hline Trap size & 1 & 101.602 & 17.146 & $<0.001$ \\
\hline Collecting fluid $\times$ Trap size & 1 & 12.812 & 2.162 & 0.150 \\
\hline Error & 36 & 5.926 & & \\
\hline \multicolumn{5}{|l|}{ Pterostichus melanarius (F) } \\
\hline Collecting fluid & 1 & 0.206 & 0.116 & 0.736 \\
\hline Trap size & 1 & 6.525 & 3.663 & 0.064 \\
\hline Collecting fluid $\times$ Trap size & 1 & 5.075 & 2.849 & 0.100 \\
\hline Error & 36 & 1.781 & & \\
\hline \multicolumn{5}{|l|}{ Pterostichus melanarius (M) } \\
\hline Collecting fluid & 1 & 0.139 & 0.097 & 0.757 \\
\hline Trap size & 1 & 12.344 & 8.592 & 0.006 \\
\hline Collecting fluid $\times$ Trap size & 1 & 4.749 & 3.306 & 0.077 \\
\hline Error & 36 & 1.437 & & \\
\hline \multicolumn{5}{|l|}{ P. niger $(\mathrm{F})$} \\
\hline Collecting fluid & 1 & 0.004 & 0.007 & 0.935 \\
\hline Trap size & 1 & 5.471 & 9.337 & 0.004 \\
\hline Collecting fluid $\times$ Trap size & 1 & 0.276 & 0.471 & 0.497 \\
\hline Error & 36 & 0.586 & & \\
\hline \multicolumn{5}{|l|}{ P. niger $(\mathrm{M})$} \\
\hline Collecting fluid & 1 & 0.005 & 0.013 & 0.911 \\
\hline Trap size & 1 & 3.514 & 8.363 & 0.006 \\
\hline Collecting fluid $\times$ Trap size & 1 & 1.174 & 2.795 & 0.103 \\
\hline Error & 36 & 0.420 & & \\
\hline \multicolumn{5}{|l|}{ Carabus nemoralis } \\
\hline Collecting fluid & 1 & 0.709 & 1.091 & 0.303 \\
\hline Trap size & 1 & 0.017 & 0.026 & 0.873 \\
\hline Collecting fluid $\times$ Trap size & 1 & 0.134 & 0.206 & 0.653 \\
\hline Error & 36 & 0.650 & & \\
\hline
\end{tabular}


Table 2. Continued.

\begin{tabular}{|c|c|c|c|c|}
\hline Source of Variation & df & MS & $\mathrm{F}$ & $p$ \\
\hline \multicolumn{5}{|l|}{ Trechus secalis } \\
\hline Collecting fluid & 1 & 1.202 & 0.918 & 0.344 \\
\hline Trap size & 1 & 0.029 & 0.022 & 0.883 \\
\hline Collecting fluid $\times$ Trap size & 1 & 2.237 & 1.709 & 0.199 \\
\hline Error & 36 & 1.309 & & \\
\hline \multicolumn{5}{|c|}{ c. Habitat type study (Lammi, Finland) } \\
\hline \multicolumn{5}{|c|}{ Calathus micropterus } \\
\hline C_F & 1 & 0.046 & 0.533 & 0.480 \\
\hline Field layer & 1 & 0.001 & 0.017 & 0.899 \\
\hline C_F $\times$ Field layer & 1 & 0.004 & 0.047 & 0.832 \\
\hline Error & 12 & 0.086 & & \\
\hline \multicolumn{5}{|l|}{ Carabus hortensis } \\
\hline C_F & 1 & 0.127 & 4.444 & 0.057 \\
\hline Field layer & 1 & 0.003 & 0.103 & 0.754 \\
\hline C_F $\times$ Field layer & 1 & $\sim 0$ & 0.007 & 0.933 \\
\hline Error & 12 & 0.028 & & \\
\hline \multicolumn{5}{|l|}{ Pterostichus niger } \\
\hline C_F & 1 & 0.012 & 0.645 & 0.437 \\
\hline Field layer & 1 & 0.001 & 0.058 & 0.814 \\
\hline C_F $\times$ Field layer & 1 & 0.045 & 2.384 & 0.149 \\
\hline Error & 12 & 0.028 & & \\
\hline \multicolumn{5}{|l|}{ P. oblongopunctatus } \\
\hline C_F & 1 & 0.826 & 10.446 & 0.007 \\
\hline Field layer & 1 & 0.103 & 1.302 & 0.276 \\
\hline C_F $\times$ Field layer & 1 & $\sim 0$ & $\sim 0$ & 0.984 \\
\hline Error & 12 & 0.079 & & \\
\hline
\end{tabular}

a - abundance data log-transformed; species richness data not transformed.

b - abundance data log-transformed; species richness data not transformed, Pterostichus melanarius (F), $P$. melanarius (M), P. niger (F), P niger (M) and Carabus nemoralis - square-root transformed; Trechus secalis - Ln-transformed.

c - data log-transformed.

melanarius was the most abundantly collected species with a total number of 712 (50\% of total catch) individuals. Trechus secalis (289 individuals, 20\%), P. niger (112 individuals, 8\%) and Carabus nemoralis (38 individuals, $3 \%$ ) were also collected in sufficient numbers to test for differences in trappability.

There was a statistically significant effect of trap size on the catch in most cases, while in most analyses performed we did not detect an effect of collecting fluid on the catch (Table 2b). Overall, large traps collected significantly more individuals (Fig. 3a) and species (Fig. 3b) than small traps. For large traps, however, the vinegar collecting fluid appeared to be more efficient than the pro- pylene-glycol mixture, while for small traps propylene-glycol was more efficient.

Large traps collected more male and female individuals of $P$. melanarius and $P$. niger (Fig. 3c-f) compared to small traps, although the difference was not statistically significant at the $5 \%$ risk level for $P$. melanarius females. We did not find a significant effect of either trap size or collecting fluid on the numbers of $C$. nemoralis (Fig. 3g) and T. secalis (Fig. 3h) collected. Although mostly statistically non-significant, there was a tendency in all analyses performed for a higher catch in large traps filled with vinegar (compared to large traps filled with propylene-glycol), and a higher catch in small traps filled with pro- 

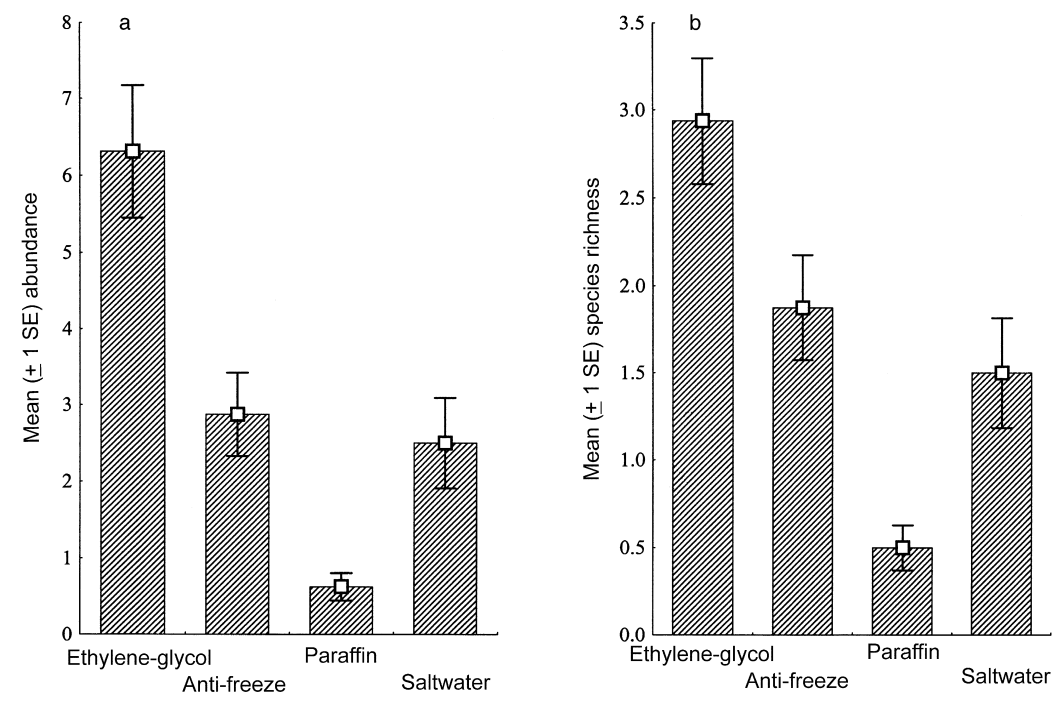

Fig. 2. - a. Mean number $( \pm 1$ SE) of carabid individuals collected by using four collecting fluids (ethyleneglycol:water mixture, commercial anti-freeze, commercial paraffin and salt water). - b. Mean number of species $( \pm 1 \mathrm{SE})$ of the same study. pylene-glycol (compared to small traps filled with vinegar) (Fig. 3).

Sex ratios of $P$. melanarius were close to parity, but for $P$. niger more females than males were collected in both small and large traps. In the small traps, we collected a mean of $7.54 \pm 1.46$ SE $P$. melanarius females, and $6.26 \pm 1.17$ SE males (1.2:1 female:male sex ratio), while in the large traps we collected a mean of $11.42 \pm 1.75$ SE females, and $12.80 \pm 1.72$ SE males $(0.89: 1$ sex ratio). For $P$. niger, we collected a mean of $0.78 \pm$ $0.12 \mathrm{SE}$ females and $0.57 \pm 0.13 \mathrm{SE}$ males (1.37:1 sex ratio) in the small traps, and $2.54 \pm 0.56 \mathrm{SE}$ females and $1.92 \pm 0.39$ SE males $(1.32$ : 1 sex ratio) in the large traps.

\subsection{Habitat type study}

The ANOVA results indicate that trappability was not significantly different among the treatments for three of the four species studied, and that the field-layer vegetation had no detectable effect for all four species studied (Table 2c, Fig. 4). However, for $P$. oblongopunctatus the catches were significantly higher in the clear-cut than in the forest. The catches of $C$. hortensis were slightly, albeit statistically non-significant at the $5 \%$ risk level, higher in the forest than in the clear-cut enclosures.

These results may indicate differences in movement behaviour in the forest and clear-cut, because directed movements may potentially lead to higher catchability than random walk in traps that have guiding walls. By looking at the mean values of the centre traps (i.e. excluding the traps at the enclosure walls) for the two Pterostichus species, we indicate that the above results may also be explained by factors other than simply directed or random movement - in general, the centre-trap catches were lower in shady habitats. In the forest-clear-cut comparisons, the catches of these species were higher in the clear-cut for $P$. oblongopunctatus, the mean catch was 1.25 $\pm 0.65 \mathrm{SE}$ in the clear-cut and $0.38 \pm 0.18 \mathrm{SE}$ in the forest enclosures $(n=13)$, and for $P$. niger the respective catches were $2.50 \pm 0.60 \mathrm{SE}$ and 1.38 $\pm 0.46 \mathrm{SE}(n=31)$. Moreover, when comparing sites with scarce field-layer vegetation to sites with well-developed field-layer vegetation, for $P$. oblongopunctatus the mean catch was $0.50 \pm 0.19$ $\mathrm{SE}$ in the former and $1.13 \pm 0.67 \mathrm{SE}$ in the latter, and for $P$. niger the respective catches were 1.75 $\pm 0.49 \mathrm{SE}$ and $2.13 \pm 0.64 \mathrm{SE}$.

\section{Discussion}

Pitfall trapping is the most popular, and most frequently used field method for studying carabid beetles (Lövei \& Sunderland 1996). Consequently, it is important to realise the shortcomings of the method and, where possible, to improve it. Our aim was to highlight some of these 

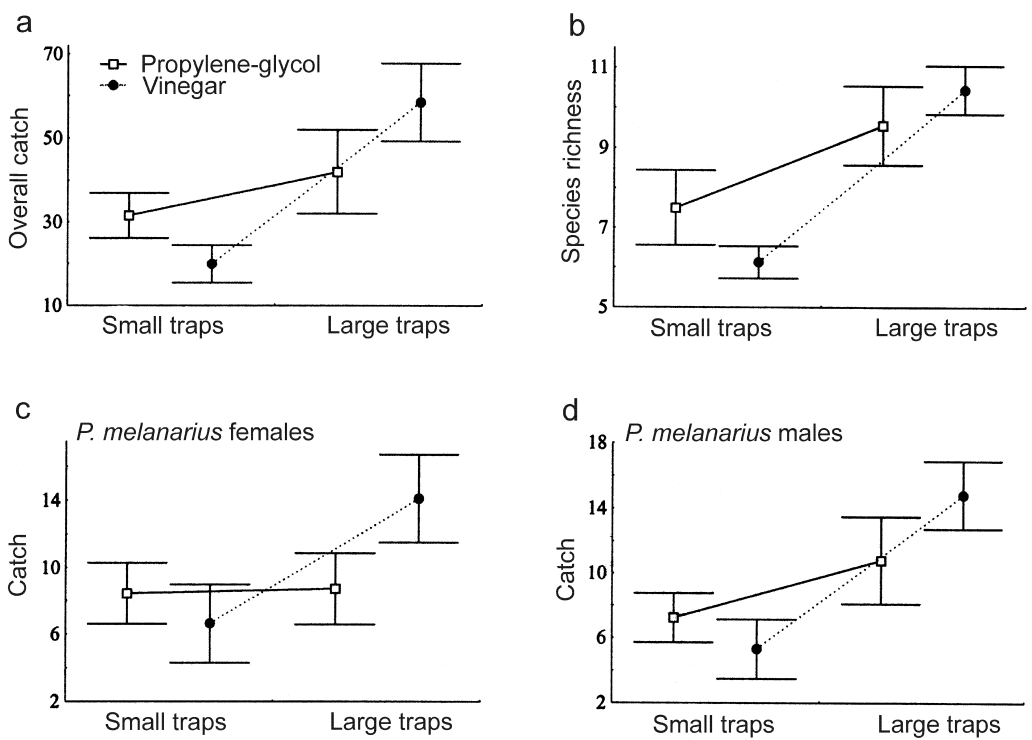

Fig. 3. Mean catches ( \pm 1 SE) in small vs. large traps and in traps with propylene-glycol vs. vinegar as collecting fluid. - a. Overall catch. - b. Species richness. - c Pterostichus melanarius females. - d. P. melanarius males. - e. $P$. niger females. - f. $P$. niger males. - g. Carabus nemoralis. $-\mathrm{h}$. Trechus secalis.

e
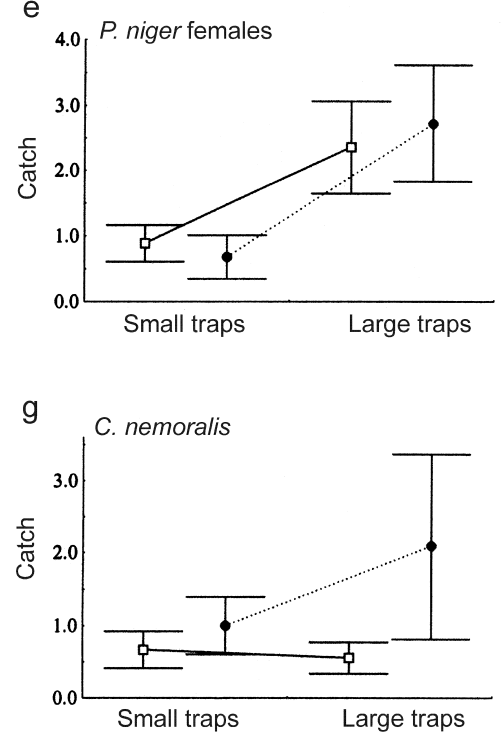
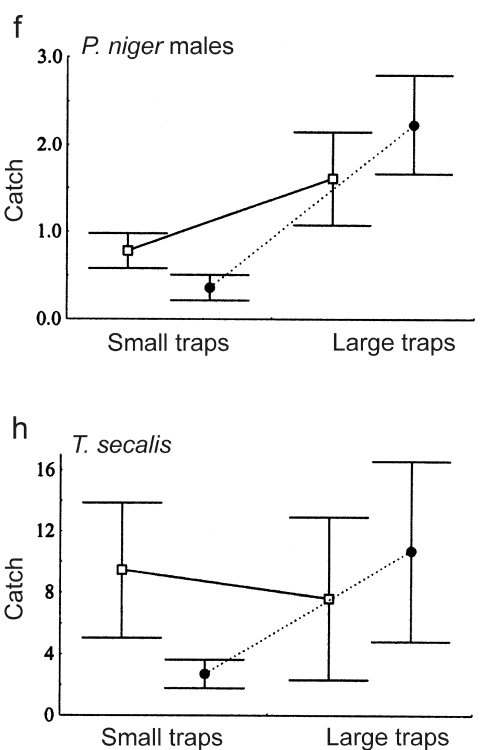

issues, with the following results; (1) collecting fluid used and the size of the trap played important roles in determining carabid catches of pitfall traps, (2) we found no significant difference in the number of male and female individuals of Pterostichus melanarius or $P$. niger collected in pitfall traps, and (3) the trappability of pitfall traps in different habitat types (here a forest and clearcut) in enclosures depended on the species trapped. For example, $P$. oblongopunctatus and to a lesser degree $C$. hortensis showed differences in catchability between habitat types, while Calathus micropterus and $P$. niger showed little differences between the habitat types sampled. Field-layer vegetation had no detectable effect on the catches.

4.1. Towards an optimal trap use: the importance of collecting fluid and trap size

Our results indicate that water-diluted glycol appears to be the best alternative when using pitfall 

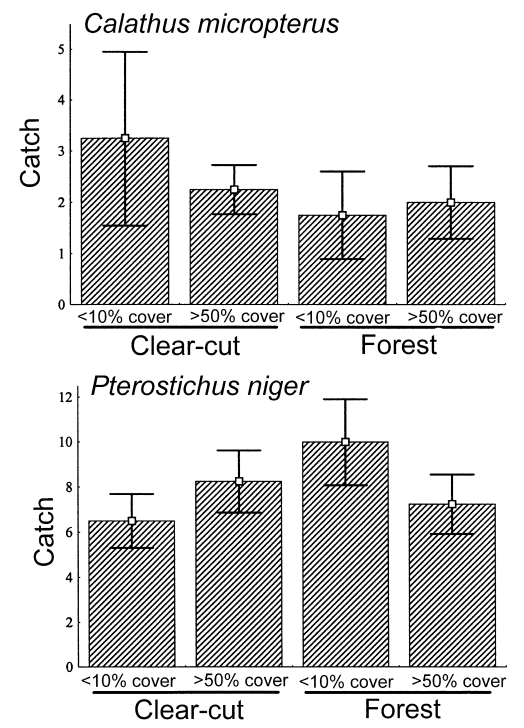
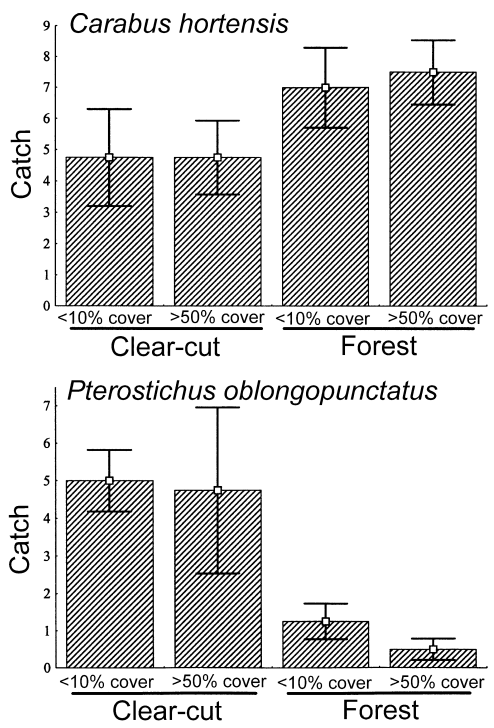

Fig. 4. Mean catches ( \pm 1 SE) of Calathus micropterus, Carabus hortensis, Pterostichus niger and $P$. oblongopunctatus in poorly $(<10 \%$ cover) and well-developed (> 50\% cover) field layers in a clear-cut and a forest patch. traps. Glycol was also more efficient in collecting carabid beetles than was salt water, a result also found by Holopainen (1992) in a forest nursery at Suonenjoki, central Finland. In general, the result may indicate that strong smelling liquids are avoided by carabids, but to our knowledge no information is available on the repelling or attractive effects of collecting fluids. Collecting efficiency also seems to vary depending on trap size.

As expected, large traps were more effective in catching carabids than smaller ones. Large traps were also shown to be optimal in collecting spiders in a Western Australian Jarrah forest (Brennan et al. 1999). There are, however, three not mutually exclusive reasons for not using very large pitfall traps. First, many small mammals (mice, shrews and voles) were found in large pitfall traps, but almost none in the smaller ones. Brennan et al. (1999) also found this and suggested that smaller traps might be more appropriate, as long as these traps are sufficiently large to collect the largest species of the target taxon. Moreover, trapping animal groups other than the target taxa may have ethical implications. Second, traps filled with decaying small mammals might influence catches by attracting e.g. carrion beetles (Silphidae) and flies (Diptera: Calliphoridae and Muscidae), and even carabid beetles. Therefore, we recommend researchers to use traps with mouth diameter 60-70 $\mathrm{mm}$ rather than larger traps, to keep the trap size constant in a given study, and perhaps to use mesh wire around the trap edges. Third, if smaller traps are more efficient in collecting small beetles, compared to large traps (see Luff 1975), it is advisable to use these small traps, as most carabid species are small. For example, of the 402 carabid species occurring in Fennoscandia, $311(77 \%)$ are smaller than $10 \mathrm{~mm}$ in size. In our second study (carried out near Nuuksio National Park), the percentages were 64 and 36, respectively (for beetle sizes see Lindroth 1985, 1986). The danger here, of course, is that the use of small traps may exclude the capture of larger carabid species. However, in the Nuuksio study the catches of small and large traps were not statistically different for the large $C$.nemoralis and the very small $T$. secalis. Perhaps the best strategy is to establish the bodysize range of the local species pool a priori, and then to perform a pilot study to establish the 'optimal' trap size, i.e. a trap that will collect small and large species efficiently.

One aspect not considered in this study is that of trap depth. Deep traps may catch more small mammals than shallow traps, as escaping from the deep ones may be more difficult. Brennan et al. (1999) suggested that larger beetles can escape from small traps, not because of their small trap mouth diameter, but because small traps are also shallower and when occasional leafs fall into these small traps, it is easier for larger beetles to 
escape. A way to try to separate these two effects would be to design an experiment using traps with the same mouth diameter but different trap depths.

\subsection{The unbearable complexity of comparing pitfall catches of different habitats}

Several examples exist of studies where pitfall catches of two (or more) rather different habitats were compared without taking into account potential differences in beetle catchability between these habitat types. For example, Honek (1988) showed that the pitfall catches were higher in sparse than in dense field-layer vegetation, and Siemann et al. (1988) showed that the vegetational richness correlated positively with the richness of invertebrate catches. Moreover, Lenski (1982) and Niemelä et al. (1993) compared pitfall catches of carabids in mature and clear-cut stands. Results like these should be treated cautiously, as they might only reflect differences in the moving behaviour of beetles in different habitat types (Wallin \& Ekbom 1988, Charrier et al. 1997), rather than real differences in numbers between habitats. Surprisingly, in the enclosures it appeared that the structure of the field-layer vegetation had no detectable effect on the total number of recapture events, but the presence of a tree canopy did influence trappability. Although only suggestive, this indicates that the moving behaviour of carabid beetles changes when they encounter unsuitable habitat, more so than when they encounter architectural differences in vegetation structure within a habitat type.

Our results at first hand perhaps mostly indicate whether a given species used random or directed movements in the clear-cut, the latter movement behaviour resulting in a higher catch because of increased probability in hitting the enclosure walls and, further, to be guided into the traps that were placed in the corners next to the walls. This may imply that, when using guiding walls around the traps, the comparability of catches of different habitat types is low — probably lower than using traps without the walls.

With the present experimental design we cannot exclude the possibility that the catchability of traps in forests and clear-cuts (or in sites with well and poorly developed field-layer vegetation) are different: in traps not placed next to the enclosure walls, the catches of two Pterostichus species were higher in the clear-cut than in the forest enclosures, and higher in enclosures with rich than poorly-developed field-layer vegetation. Moreover, Charrier et al. (1997) showed that radiotracked individuals of the forest carabid Abax parallelepipedus were inactive for shorter periods and moved longer distances in the favoured forest habitat, compared to other habitats. Therefore, a crucial question concerning the effect of habitat on catches is whether the 'direction' of the effect can be predicted. At first this seems to demand only knowledge on the habitat specificity of a given species, and on the microclimatic conditions of the studied habitat types. For example, light, moisture and wind conditions may vary considerably between mature forest and clear-cut stands (Matlack 1993). As was shown for two Pterostichus species (Baars 1979) and for the chrysomelid beetle Trirhabda borealis (Goodwin \& Fahrig 2002), beetles may be more active and use directed movements in unfavourable conditions (lack of food, poor habitat, etc.), increasing the likelihood of capturing individuals in the enclosures placed in these unfavourable habitats. However, it is also known that carabid beetles move randomly in favoured habitat (Wallin \& Ekbom 1988, Charrier et al. 1997), thereby increasing the likelihood of being captured.

This dilemma in predicting the effect of habitat on carabid activity is a serious one. Most obviously is the fact that we may not be able to reliably predict the activity or density of a particular species in a particular habitat type, using pitfall traps. This is because local activity and density are likely to be influenced by temperature, how starved the beetle is, whether there is shelter around, and a myriad of other obvious and not so obvious factors. Alternatively, beetle habitat associations recorded in the literature could be incorrect (being often based on biased pitfall-trapping comparisons), and once accurate information on a carabid beetle's 'preferred' habitat is available, better predictions may be possible. Radio-tracking or mark-recapture techniques might be reliable solutions for comparing different types of habitat and to shed more light on species habitat associations. 


\subsection{Ecological findings and conclusions}

In our habitat study, there were also important ecological findings. We showed that $P$. niger and C. micropterus were quite evenly captured from different types of forest habitats. This supports Kinnunen (1999) and Heliölä et al. (2001), who showed that $P$. niger is a habitat generalist (with respect to canopy closure) and the same probably holds true for $C$. micropterus in the clear-cuts (logged 1-2 years earlier) and mature, closed stands. Furthermore, the primary literature classifies $P$. oblongopunctatus as a forest species (Lindroth 1986), even though Koivula (2002) caught it almost equally abundantly in matureforest and in clear-cut stands (with the same forest type as in our study). Concerning the centre traps, we collected this species more frequently from the clear-cut than from the forest, and more often from enclosures with rich than from those with poor field-layer vegetation. These discrepancies in catch frequency may make conclusions regarding the differences in the carabid faunas of different habitats difficult and unreliable. Finally, although more $C$. hortensis individuals were captured from forest enclosures, supporting results from Niemelä et al. (1993) and Koivula (2002), this species may also tolerate logging and survive in the clear-cuts, at least in the short term.

Although this paper deals with pitfall trapping, the same problems (of liquid used, trap size and habitat) probably affect other passive trapping methods. The results of $P$. oblongopunctatus and $C$. hortensis indicate that there are problems in comparing within-species catches (let alone between two or more different species) from different environmental types. This point is accentuated in a study by Desender \& Maelfait (1986) who showed that carabid beetle captures in pitfall traps in enclosures were much better correlated to catches in soil samples - thought of as a reliable density estimate - than to catches in open pitfall traps. There are, however, no straightforward solutions for this (except for testing the effect of the studied habitats for every species), since for large-effort studies there are no realistic (cheap and easy) alternatives to pitfall trapping.
Acknowledgements. We thank Zoe Brockhelhurst, Sven Bourquin, Anna Hahtola, Stephen Venn and Eden Wildy for fieldwork assistance. Katja Matveinen, Jari Niemelä, Juha Siitonen and Harri Tukia provided valuable advice in the planning phase of the habitat type study. The universities of Natal, South Africa and Helsinki, Finland provided funding for this study. LH was financed by the Lammi Biological Station, and MK by the Oskar Öflund foundation. Two anonymous referees provided constructive comments.

\section{References}

Baars, M. A. 1979: Catches in pitfall traps in relation to mean densities of carabid beetles. - Oecologia 41: 2546.

Brennan, K. E. C., Majer, J. D. \& Reygaert, N. 1999: Determination of an optimal pitfall trap size for sampling spiders in a Western Australian Jarrah Forest. — Journal of Insect Conservation 3: 1-11.

Cajander, A. K. 1949: Forest types and their significance. - Acta Forestalia Fennica 56: 1-71.

Charrier, S., Petit, S. \& Burel, F. 1997: Movements of Abax parallelepipedus (Coleoptera, Carabidae) in woody habitats of a hedgerow network landscape: a radio-tracking study. - Agriculture, Ecosystems and Environment 61: 133-144.

Den Boer, P. J. 1986: Carabids as objects of study. — In: Den Boer, P. J., Luff, M. L., Mossakowski, D. \& Weber, F. (eds.), Carabid Beetles, their Adaptations and Dynamics: 539-551. Stuttgart, Gustav Fischer.

Desender, K. \& Maelfait, J.-P. 1986: Pitfall trapping within enclosures: a method for estimating the relationship between the abundances of coexisting carabid species (Coleoptera: Carabidae). — Holarctic Ecology 9: 245250.

Donnelly, D. \& Giliomee, J. H. 1985: Community structure of epigaeic ants (Hymenoptera: Formicidae) in fynbos vegetation in the Jonkershoek Valley. - Journal of Entomological Society of South Africa 48: 247-257.

Goodwin, B. J. \& Fahrig, L. 2002: Effect of landscape structure on the movement behaviour of a specialized goldenrod beetle, Trirhabda borealis. — Canadian Journal of Zoology 80: 24-35.

Greenslade, P. J. M. 1964: Pitfall trapping as a method for studying populations of Carabidae (Coleoptera). Journal of Animal Ecology 33: 301-310.

Halsall, N. B. \& Wratten, S. D. 1988: The efficiency of pitfall trapping for polyphagous predatory Carabidae. — Ecological Entomology 13: 293-299.

Heliölä, J., Koivula, M. \& Niemelä, J. 2001: Distribution of carabid beetles (Coleoptera, Carabidae) across boreal forest-clearcut ecotone. - Conservation Biology 15: $370-377$. 
Holopainen, J. K. 1992: Catch and sex ratio of Carabidae (Coleoptera) in pitfall traps filled with ethylene glycol or water. - Pedobiologia 36: 257-261.

Honek, A. 1988: The effect of crop density and microclimate on pitfall trap catches of Carabidae, Staphylinidae (Coleoptera), and Lycosidae (Araneae) in cereal fields. - Pedobiologia 32: 233-242.

Hurlbert, S. H. 1984: Pseudoreplication and the design of ecological field experiments. - Ecological Monographs 54: 187-211.

Huusela-Veistola, E. 1996: Effects of pesticide use and cultivation techniques on ground beetles (Col., Carabidae) in cereal fields. - Annales Zoologici Fennici 33: 197-205.

Kinnunen, H. 1999: In search of spatial scale - carabid beetle communities in agricultural landscapes. - Ph.D. thesis, University of Helsinki.

Koivula, M. 2002: Boreal carabid-beetle (Coleoptera, Carabidae) assemblages in thinned uneven-aged and clear-cut spruce stands. - Annales Zoologici Fennici 39: 131-149.

Lenski, R. E. 1982: The impact of forest cutting on the diversity of ground beetles (Coleoptera: Carabidae) in the southern Appalachians. - Ecological Entomology 7: $385-390$

Lindroth, C. H. 1985: The Carabidae (Coleoptera) of Fennoscandia and Denmark. Fauna Entomologica Scandinavica 15, part 1. - Scandinavian Science Press Ltd., Leiden.

Lindroth, C. H. 1986: The Carabidae (Coleoptera) of Fennoscandia and Denmark. Fauna Entomologica Scandinavica 15, part 2. - Scandinavian Science Press Ltd., Leiden.

Luff, M. L. 1975: Some features influencing the efficiency of pitfall traps. - Oecologia 19: 345-357.

Luff, M. L. 1996: Use of carabids as environmental indicators in grasslands and cereals. - Annales Zoologici Fennici 33: 185-195.

Lövei, G. L. \& Sunderland, K. D. 1996: Ecology and behavior of ground beetles (Coleoptera: Carabidae). Annual Review of Entomology 41: 231-256.

Marsh, A. C. 1984: The efficiency of pitfall traps for determining the structure of a desert ant community. - Journal of Entomological Society of South Africa 47: 115-120.

Matlack, G. R. 1993: Microenvironment variation within and among forest edge sites in the eastern United States. - Biological Conservation 66: 185-194.

Mommertz, S., Schauer, C., Kösters, N., Lang, A. \& Filser, J. 1996: A comparison of D-vac suction, fenced and unfenced pitfall trap sampling of epigeal arthropods in agro-ecosystems. - Annales Zoologici Fennici 33: $117-124$.
Niemelä, J., Spence, J. R., Langor, D. W., Haila, Y. \& Tukia, H. 1993: Logging and boreal ground beetle assemblages on two continents: implications for conservation. In: Gaston, K. J., New, T. R. \& Samways, M. J. (eds.), Perspectives in insect conservation: 29-50. Intercept Publishers, Ltd., Andover, Hampshire.

Oliver, I. \& Beattie, A. J. 1993: A possible method for the rapid assessment of biodiversity. - Conservation Biology 7: 562-568.

Oliver, I. \& Beattie, A. J. 1996: Designing a cost-effective invertebrate survey: a test of methods for rapid assessment of biodiversity. - Ecological Applications 6: 594-607.

Péringuey, L. 1896: The Coleoptera of South Africa. Part II. Carabidae. - Transactions of the South African Philosophical Society 7: 125-623.

Purvis, G. \& Fadl, A. 1996: Emergence of Carabidae (Coleoptera) from pupation: a technique for studying the 'productivity' of carabid habitats. - Annales Zoologici Fennici 33: 215-223.

Samways, M. J. 1983: Community structure of ants (Hymenoptera: Formicidae) in a series of habitats associated with cities. — Journal of Applied Ecology 20: 833847.

Siemann, E., Tilman, D., Haarstad, J. \& Ritchie, M. 1988: Experimental tests of the dependence of arthropod diversity on plant diversity. - American Naturalist 152: 738-750.

Southwood, T. R. E. 1978: Ecological methods: with particular reference to the study of insect populations. 2nd edition. - Chapman and Hall, London.

Spence, J. R. \& Niemelä, J. K. 1994: Sampling carabid assemblages with pitfall traps: the madness and the method. - Canadian Entomologist 126: 881894.

Törmälä, T. 1982: Evaluation of five methods of sampling field layer arthropods, particularly the leafhopper community, in grassland. - Annales Entomologici Fennici 48: 1-16.

Van den Berghe, E. 1992: On pitfall trapping invertebrates. - Entomological News 103: 149-156.

Wallin, H. \& Ekbom, B. S. 1988: Movements of carabid beetles (Coleoptera: Carabidae) inhabiting cereal fields: a field tracing study. - Oecologia 77: 39-43.

Wallin, H. \& Ekbom, B. 1994: Influence of hunger level and prey densities on movement patterns in three species of Pterostichus beetles (Coleoptera: Carabidae). - Population Ecology 23: 1171-1181.

Ward, D. F., New, T. R. \& Yen, A. L. 2001: Effects of pitfall trap spacing on the abundance, richness and composition of invertebrate catches. - Journal of Insect Conservation 5: 47-53. 
Appendix. Carabid beetles collected near Nuuksio National park, Finland. Prop-glyc = propylene-glycol.

\begin{tabular}{|c|c|c|c|c|c|}
\hline \multirow[b]{2}{*}{ Species } & \multicolumn{3}{|c|}{ Small traps } & \multicolumn{2}{|c|}{ Large traps } \\
\hline & Size $(\mathrm{mm})$ & Prop-glyc & Vinegar & Prop-glyc & Vinegar \\
\hline Agonum fuliginosum (Panzer) & $6-8$ & 4 & 1 & 8 & 3 \\
\hline Agonum obscurum (Herbst) & $5-7$ & - & - & 1 & - \\
\hline Amara aenea (Degeer) & $6-9$ & 5 & 2 & 1 & 2 \\
\hline Amara communis (Panzer) & $6-7$ & 3 & - & 19 & 14 \\
\hline Amara curta Dejean & $6-7$ & - & - & - & 1 \\
\hline Amara eurynota (Panzer) & $10-13$ & - & - & 1 & 2 \\
\hline Amara famelica Zimmermann & 7-9 & 1 & - & - & - \\
\hline Amara lunicollis Schiødte & $7-9$ & 1 & - & 10 & 11 \\
\hline Amara montivaga Sturm & $8-9$ & - & - & 1 & - \\
\hline Amara nitida Sturm & $7-9$ & - & - & - & 1 \\
\hline Amara quenseli (Schönherr) & $6-9$ & - & - & 1 & 2 \\
\hline Amara tibialis (Paykull) & $4-6$ & - & - & 1 & - \\
\hline Anisodactylus binotatus (F.) & $10-13$ & - & - & - & 1 \\
\hline Bembidion guttula (F.) & $3-4$ & 6 & 6 & 8 & 2 \\
\hline Bembidion lampros (Herbst) & $3-4$ & 1 & 1 & - & 5 \\
\hline Bembidion minimum (F.) & $2-3$ & 1 & - & 2 & - \\
\hline Bembidion properans (Stephens) & $3-4$ & - & - & 1 & - \\
\hline Bembidion quadrimaculatum (L.) & $3-4$ & - & - & 2 & - \\
\hline Bradycellus caucasicus (Chaudoir) & $3-4$ & - & - & - & 1 \\
\hline Carabus granulatus L. & $16-23$ & - & - & - & 1 \\
\hline Carabus hortensis L. & $22-28$ & - & 1 & 3 & 2 \\
\hline Carabus nemoralis Müller & $22-26$ & 6 & 8 & 5 & 19 \\
\hline Clivina fossor (L.) & 6-7 & - & 1 & 2 & 2 \\
\hline Dromius sigma (Rossi) & $3-4$ & - & - & - & 3 \\
\hline Harpalus latus (L.) & $8-11$ & - & - & 3 & - \\
\hline Harpalus rufipes (Degeer) & $10-17$ & - & - & 2 & 2 \\
\hline Harpalus tardus (Panzer) & $8-11$ & - & - & 2 & - \\
\hline Lebia chlorocephala (Hoffmann) & $6-8$ & - & - & 1 & 1 \\
\hline Leistus terminatus (Hellwig in Panzer) & $6-8$ & 1 & - & - & 1 \\
\hline Loricera pilicornis (F.) & $6-9$ & 1 & 3 & 1 & 3 \\
\hline Patrobus assimilis Chaudoir & $8-9$ & - & 1 & 2 & - \\
\hline Patrobus atrorufus (Ström) & $7-10$ & 1 & - & 3 & 2 \\
\hline Pterostichus cupreus (L.) & $11-13$ & 2 & 1 & 5 & 6 \\
\hline Pterostichus diligens (Sturm) & $5-7$ & 1 & 2 & - & 1 \\
\hline Pterostichus melanarius (f) (Illiger) & $12-18$ & 76 & 59 & 84 & 136 \\
\hline Pterostichus melanarius (m) (Illiger) & $12-18$ & 65 & 46 & 104 & 142 \\
\hline Pterostichus niger (f) (Schaller) & $15-20$ & 8 & 6 & 23 & 27 \\
\hline Pterostichus niger (m) (Schaller) & $15-20$ & 7 & 3 & 16 & 22 \\
\hline Pterostichus nigrita (Paykull) & $9-13$ & - & 1 & 3 & - \\
\hline Pterostichus oblongopunctatus (F.) & $10-12$ & - & 1 & - & 2 \\
\hline Pterostichus strenuus (Panzer) & 6-7 & 5 & 3 & 6 & 4 \\
\hline Pterostichus versicolor (Sturm) & $9-12$ & 3 & 2 & 4 & 33 \\
\hline Trechus micros (Herbst) & 4-5 & 1 & - & - & - \\
\hline Trechus secalis (Paykull) & 4 & 85 & 23 & 75 & 106 \\
\hline Trichocellus placidus (Gyllenhal) & $4-6$ & - & - & 2 & - \\
\hline
\end{tabular}

